\title{
Osimertinib-Induced Unilateral Diffuse Alveolar Hemorrhage in a Patient With Pulmonary Adenocarcinoma
}

\author{
Shiho Saeki ${ }^{a}$, Kanako Nishimatsu ${ }^{\text {a }}$, Shoichi Ihara ${ }^{\text {a }}$, Seigo Minami ${ }^{a}$, b
}

\begin{abstract}
A 70-year-old man with lung adenocarcinoma was admitted to our hospital due to progressive dyspnea, 4 months after osimertinib initiation. His chest radiograph and computed tomography revealed ground-glass opacities and consolidations dominantly in the upper left lung. He took neither antiplatelet nor anticoagulation agent. No abnormality in coagulation was detected. Bronchoalveolar lavage fluid (BALF) became serially and increasingly hemorrhagic, and confirmed the diagnosis of alveolar hemorrhage. After steroid pulse therapy and withdrawal of osimertinib, his condition gradually improved, accompanied by regression of ground-glass opacities and consolidations. Osimertinib causes not only interstitial pneumonia but also alveolar hemorrhage. The consolidations may spread not bilaterally, but be localized unilaterally. We have to keep this rare adverse event in mind, and consider immediate withdrawal of osimertinib and treatment with steroid. Increased lymphocytes in the BALF may be a potential indicator of sensitivity to steroid and favorable prognosis in diffuse alveolar hemorrhage.
\end{abstract}

Keywords: Diffuse alveolar hemorrhage; Osimertinib; Epidermal growth factor receptor tyrosine kinase inhibitor; Bronchoscopy; Bronchoalveolar lavage; Drug-induced interstitial pneumonia; Nonsmall cell lung cancer; Steroid pulse; Lymphocyte; Neutrophil

\section{Introduction}

Osimertinib is a third-generation irreversible tyrosine kinase inhibitor of the epidermal growth factor receptor (EGFR-TKI). In the FLAURA trial, osimertinib improved progression-free survival in previously untreated patients with locally advanced or metastatic EGFR-mutated non-small cell lung cancer (NSCLC), compared with erlotinib and gefitinib. Therefore,

Manuscript submitted April 16, 2021, accepted April 30, 2021

Published online May 13, 2021

aDepartment of Respiratory Medicine, Osaka Police Hospital, 10-31 Kitayama-cho, Tennoji-ku, Osaka 543-0035, Japan

${ }^{b}$ Corresponding Author: Seigo Minami, Department of Respiratory Medicine, Osaka Police Hospital, 10-31 Kitayama-cho, Tennoji-ku, Osaka-City, Osaka 543-0035, Japan. Email: seigominami@oph.gr.jp

doi: https://doi.org/10.14740/jmc3702 osimertinib has become a standard drug as the first-line treatment for these patients. Owing to highly selective inhibition of mutated $E G F R$ and lower activity against wild-type $E G F R$, less than $5 \%$ of patients develop significant pulmonary toxicity [1]. Digestive and dermatological symptoms are representative as adverse effects of osimertinib. On the other hand, interstitial lung disease (ILD) is recognized as an infrequent, but serious adverse effect associated with osimertinib.

Diffuse alveolar hemorrhage (DAH) is characterized by the accumulation of intra-alveolar erythrocytes originating from the alveolar capillaries [2]. Various diseases cause DAH. As the causes of DAH, the following two etiologies are well known: 1) pulmonary capillaritis, i.e., anti-neutrophil cytoplasmic antibodies (ANCA)-associated granulomatous vasculitis, microscopic polyangiitis and Goodpasture syndrome; and 2 ) various drugs, such as propyluracil, anticoagulants and amiodarone $[2,3]$. The precise prevalence of each cause remains unknown. EGFR-TKI is a rare drug that causes DAH. As pulmonary adverse effects of osimertinib, acute pneumonitis, eosinophilic pneumonia and fleeting asymptomatic infiltrates on imaging have been reported [1].

We herein report a case of DAH, which occurred during osimertinib for pulmonary adenocarcinoma and resolved after withdrawal of osimertinib and steroid treatment.

\section{Case Report}

A 70-year-old man visited another hospital because of a persistent cough for 2 months. The right pleural effusion was found on a chest radiograph. Computed tomography (CT) of the chest revealed a mass of $4 \mathrm{~cm}$ in diameter in the right upper lobe and bilateral multiple lung nodules (Fig. 1a). He was diagnosed as adenocarcinoma (cT2aN0M1a, c-stageIVA) with EGFR exon 19 deletion by transbronchial biopsy. Endoscopic bronchial occlusion with endobronchial Watanabe spigot (EWS), silicone-made bronchial fillers, was performed twice for management of intractable iatrogenic pneumothorax after bronchoscopy. Then he started osimertinib $(80 \mathrm{mg} /$ day $)$. He also had prostatic hypertrophy and had been treated with tamsulosin. He had no allergy, socially drank and was an ex-smoker with a history of 15 pack-years of cigarette smoking. At the start of osimertinib, his Eastern Cooperative Oncology Group Performance Status (ECOG-PS) was 0. He was prescribed with dextromethorphan and tamsulosin at that time, but took neither antiplatelet nor anticoagulation agent. Two months after the 

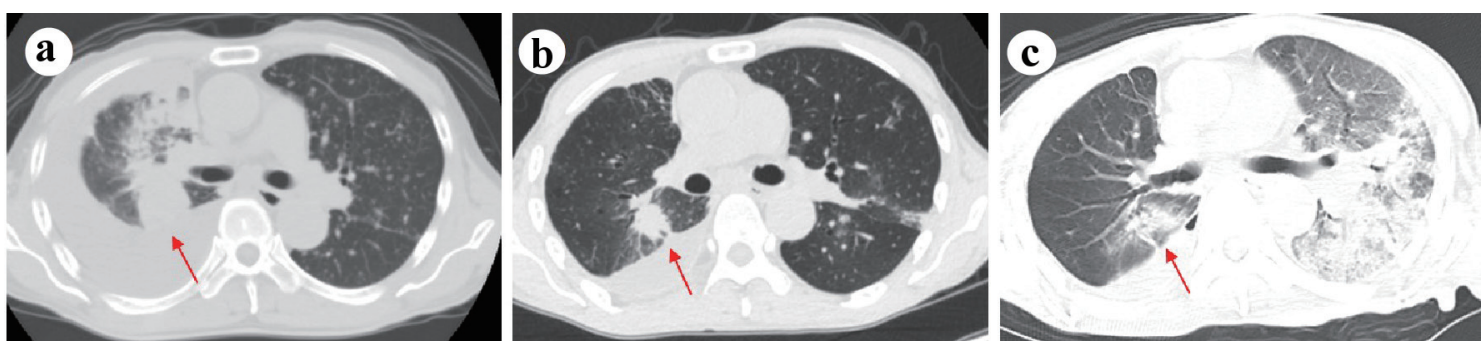

Figure 1. Chest computed tomography on the diagnosis (a), 2 months after the start of osimertinib (b) and on admission (c).
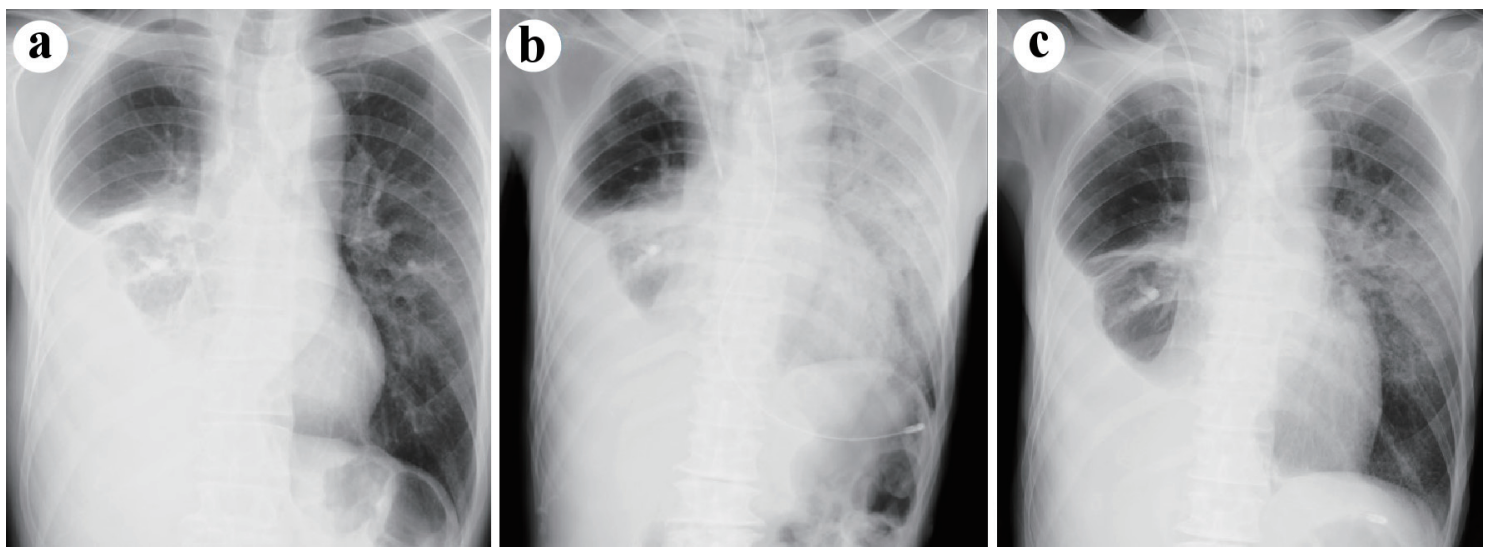

Figure 2. Chest radiographs on 2 months after the initiation of osimertinib (a), on admission (b), and (c) at the time of extubation (on the hospital day 11).

initiation of osimertinib, both primary tumor in the right upper lobe and metastatic lesions in the bilateral lungs reduced, and no ground-grass opacity was detected (Figs. 1b, 2a).

\section{Investigations}

Four months after osimertinib initiation, he required an emergency admission to our hospital due to progressive dyspnea. His consciousness at the arrival to our emergency room (ER) was clear, and his vital signs revealed a temperature of $35.8^{\circ} \mathrm{C}$, a blood pressure of $150 / 98 \mathrm{~mm} \mathrm{Hg}$, a pulse of 113 beats/min, a percutaneous oxygen saturation of $78 \%$ under bag valve mask ventilation, and a respiratory rate of 24 breaths/min. His breath sounds were decreased, and coarse crackles were audible bilaterally. His limbs were cold with livedo reticularis and cyanosis. There was no jugular venous distention. In the peripheral venous blood sampling, the leukocyte count was $11,500 / \mu \mathrm{L}$, C-reactive protein level was $9.49 \mathrm{mg} / \mathrm{dL}$, platelet count was $30.7 \times 10^{4} / \mu \mathrm{L}$. No abnormality of coagulation was revealed, prothrombin time-international normalized ratio was 1.27 and activated partial thromboplastin time was $33.9 \mathrm{~s}$. The arterial blood gas analysis (under bag valve mask of oxygen flow of 15 $\mathrm{L} / \mathrm{min}$ ) showed lactic acidosis, $\mathrm{pH}$ was 7.165 and lactate was $11.8 \mathrm{mmol} / \mathrm{L}$. The urine test was normal, except for hematuria due to prostatic hypertrophy. Sputum, urine and blood bacte-
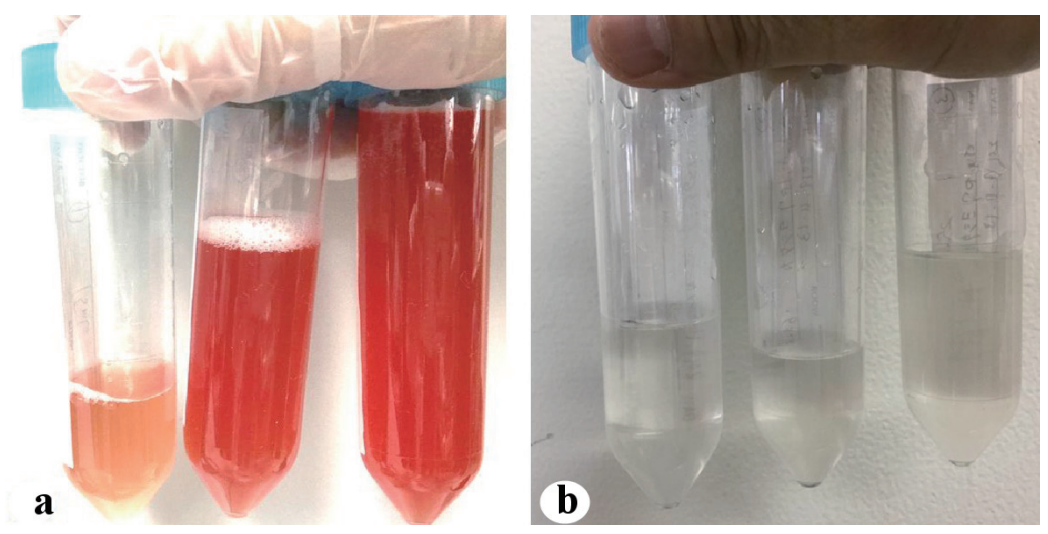

Figure 3. The BALFs on the hospital day 1 (a) and 9 (b). BALF: bronchoalveolar lavage fluid. 
Table 1. Summary of Previous Cases of Alveolar Hemorrhage Induced by EGFR-TKI

\begin{tabular}{|c|c|c|c|c|c|c|c|c|}
\hline $\begin{array}{l}\text { Author } \\
\text { (year) }\end{array}$ & $\begin{array}{l}\text { EGFR- } \\
\text { TKI (line) }\end{array}$ & $\begin{array}{l}\text { Age (years), } \\
\text { sex, country }\end{array}$ & Symptoms & Mutations & $\begin{array}{l}\text { Inter- } \\
\text { val }^{\mathrm{a}}\end{array}$ & $\begin{array}{l}\text { Steroid use } \\
\text { (initial dose) }\end{array}$ & $\begin{array}{l}\text { Respiratory } \\
\text { management }\end{array}$ & $\begin{array}{l}\text { BFS (differen- } \\
\text { tial cell count) }\end{array}$ \\
\hline $\begin{array}{l}\text { Ieki et al, } \\
2003 \text { [4] }\end{array}$ & Gef (4th) & 56 M, Japan & $\begin{array}{l}\text { Dyspnea, } \\
\text { bloody phlegm }\end{array}$ & ND & 4 weeks & $\begin{array}{l}\text { High-dose } \\
\text { mPSL }\end{array}$ & NPPV & $\begin{array}{l}\text { Performed }(90 \% \\
\text { Lym, } 10 \% \text { Neu) }\end{array}$ \\
\hline $\begin{array}{l}\text { Yano et al, } \\
2005[5]\end{array}$ & Gef (4th) & 62 F, Japan & ND & ND & $\begin{array}{l}13 \\
\text { months }\end{array}$ & $\begin{array}{l}\operatorname{mPSL}(1,000 \\
\mathrm{mg} / \text { day })\end{array}$ & ND & ND \\
\hline $\begin{array}{l}\text { Zhao et al, } \\
2014 \text { [6] }\end{array}$ & $\operatorname{Erl}(1 \mathrm{st})$ & $40 \mathrm{M}$, China & Fever & $\begin{array}{l}\text { Esophageal } \\
\text { carcinoma (SQ) }\end{array}$ & 1 month & $\begin{array}{l}\mathrm{mPSL}(1,000 \\
\mathrm{mg} / \text { day })\end{array}$ & NPPV & Performed (ND) \\
\hline $\begin{array}{l}\text { Forte et al, } \\
2019 \text { [1] }\end{array}$ & $\begin{array}{l}\text { Osim } \\
\text { (multiple) }\end{array}$ & $65 \mathrm{~F}, \mathrm{USA}$ & $\begin{array}{l}\text { Dyspnea, } \\
\text { fatigue }\end{array}$ & Ex19del,T790M & $\begin{array}{l}5 \\
\text { months }\end{array}$ & $\begin{array}{l}\text { mPSL }(1,000 \\
\text { mg/day })\end{array}$ & Intubated & Performed (ND) \\
\hline $\begin{array}{l}\text { Komori et } \\
\text { al, } 2019 \text { [7] }\end{array}$ & Osim (2nd) & 75 F, Japan & Bloody phlegm & L858R, T790M & $\begin{array}{l}2 \\
\text { months }\end{array}$ & $\begin{array}{l}\text { PSL }(0.5 \\
\mathrm{mg} / \mathrm{kg})\end{array}$ & ND & $\begin{array}{l}\text { Performed (20\% } \\
\text { Lym, } 8 \% \mathrm{Neu})\end{array}$ \\
\hline
\end{tabular}

aThe interval time from the start of EGFR-TKI to the onset of symptoms. EGFR-TKI: epidermal growth factor receptor tyrosine kinase inhibitor; Ex: exon; F: female; Gef: gefitinib; Lym: Iymphocytes; M: male; mPSL: methylprednisolone; ND: not described; Neu: neutrophils; NPPV: non-invasive positive pressure ventilation; Osim: osimertinib; SQ: squamous carcinoma; BFS: bronchial fiberscope.

rial cultures were all negative. Electrocardiography showed sinus rhythm with normal range of QTc time (472 ms). Chest radiographs at ER visit showed unilateral diffuse ground-grass opacities dominantly in the left lung field (Fig. 2b). Chest CT revealed diffuse ground-grass opacities and consolidation in the left upper and lower lobe, dominantly upper lobe (Fig. 1c). At that time, we suspected drug-induced interstitial pneumonia or infectious disease. Neither bleeding nor inflammation was not visually observed in his bronchial tracts by bronchoscopy. Bronchoalveolar lavage fluid (BALF) from the left B5 (fluid recovery rate $65 \%$ ) became serially and increasingly hemorrhagic (Fig. 3a). The total cell count in the BALF was $3.3 \times$ $105 / \mathrm{mL}$, and differential cell count showed $54.5 \%$ of $1 y m-$ phocytes, $43.5 \%$ of neutrophils, $1.5 \%$ of macrophage, $0.5 \%$ of eosinophils and 5.13 of cluster of differentiation (CD)4/ $\mathrm{CD} 8$ ratio. In the BALF, bacterial cultures were negative and no malignant cell was detected. Thereafter, proteinase 3 (PR3) ANCA, myeloperoxidase (MPO) ANCA and anti-glomerular basement membrane (GBM) antibodies were all negative.

\section{Diagnosis}

The patient was diagnosed with osimertinib-induced DAH.

\section{Treatment}

We discontinued osimertinib, and then started steroid pulse therapy with methylprednisolone at $1,000 \mathrm{mg} /$ day for 3 consecutive days, followed by steroid maintenance therapy with prednisolone $(1.25 \mathrm{mg} / \mathrm{kg} /$ day $)$. The consolidation regressed after the steroid pulse therapy. The second BALF from the left B5 (fluid recovery rate $41 \%$ ) on the hospital day 9 was not bloody (Fig. 3b). The total cell count in the second BALF was $1.3 \times 10^{5} / \mathrm{mL}$, and differential cell count showed $14.5 \%$ of lymphocytes, $2.5 \%$ of neutrophils, $83.0 \%$ of macrophage, $0 \%$ of eosinophils, and 1.73 of $\mathrm{CD} 4 / \mathrm{CD} 8$ ratio. His pressure of arterial oxygen to fractional inspired oxygen concentration $\mathrm{PaO}_{2} / \mathrm{FiO}_{2}$ (PF) ratio improved significantly from 77.6 on the hospital day 1 to 182 on the hospital day 11. Thus, he was extubated on the hospital day 11 (Fig. 2c). Prednisolone and $\mathrm{O}_{2}$ inhalation were gradually tapered.

\section{Follow-up and outcomes}

He was discharged home on the hospital day 91. Considering the risk of recurrence of DAH and decreased ECOG-PS from 0 to 3 , he was followed without further aggressive chemotherapy. Three months after the discharge, he died of lung cancer progression.

\section{Discussion}

This was a rare case of osimertinib-induced DAH. To our knowledge, there were only two osimertinib-induced and four other EGFR-TKI-induced DAH cases (Table 1) [1, 4-8]. We could not find a report of DAH induced by other EGFR-TKIs; afatinib and dacomitinib, and anti-EGFR antibodies; cetuximab and panitumumab.

Although the mechanisms of drug-induced DAH remains unidentified, a direct toxicity to type II pneumocytes, tracheal epithelial cells and vascular endothelial cells by cytotoxic drugs and activation of immune system cells may play a key role [7]. In some previous literatures of TKI-induced DAH, this cytotoxic mechanism was assumed as the cause of DAH 
$[4,6,8]$. In addition to inhibition of cancer cell proliferation and tumor growth, EGFR-TKI also suppresses angiogenesis and promotes apoptosis of vascular endothelial cells $[9,10]$.

Compared with the previous cases of EGFR-TKI-induced $\mathrm{DAH}$, our case was interesting in distribution of DAH shadow, i.e., unilaterally localized consolidations. A 65-year-old US woman required intubated mechanical ventilation and then improved by steroid pulse therapy [1]. Her CT images were similar to our case in that the diffuse consolidation did not bilaterally spread, but was localized in the left upper lobe. However, the reason why DAH happened dominantly in the unilateral lung remains uncertain.

In our case, not only bronchoscopy but also BAL was necessary for the detection of DAH. If we had not performed BAL at the ER visit, we might have assumed infectious pneumonia and treated him only with antibiotics. We should not hesitate to perform bronchoscopy with BAL when we encounter intractable or atypical pneumonia during EGFR-TKI treatment.

Our case was also interesting in the report of differential cell counts in the BALF. Differential cell counts in the BALF may be a potential and useful marker of sensitivity to steroid and prognosis in DAH. There were only two reports of differential cell counts in the BALF of EGFR-TKI-induced DAH $[4,7]$. A 56-year-old Japanese man with $90 \%$ of lymphocytes and $10 \%$ of neutrophils in the BALF improved after high dose of methylprednisolone [4]. Another 75-year-old Japanese woman with $20 \%$ of lymphocytes and $8 \%$ of neutrophils in the BALF recovered without steroid pulse therapy [7]. In idiopathic pulmonary fibrosis (IPF), differential cell counts in the BALF were not correlated with steroid sensitivity and prognosis [11]. Fibrosis was reported to be of unfavorable prognostic relevance in acute exacerbation of ILDs $[12,13]$. On the other hand, when we find diffuse consolidations with increased lymphocytes $(\geq 20 \%)$ in the BALF, we should consider other differential diagnoses except IPF [12]. Cytologically increased lymphocytes in the BALF and histologically small fibrotic changes may be favorable prognostic indicators of DAH. However, bronchoscopic specimen with biopsy is difficult at a risk of hemorrhagic worsening in DAH. Thus, BALF may be clinically available and useful as a prognostic marker of DAH.

\section{Conclusions}

Osimertinib causes not only interstitial pneumonia but also alveolar hemorrhage. The consolidations may spread not bilaterally, but be localized unilaterally. We have to keep this rare adverse event in mind, and consider immediate withdrawal of osimertinib and treatment with steroid. Increased lymphocytes in the BALF may be a potential indicator of sensitivity to steroid and favorable prognosis in $\mathrm{DAH}$.

\section{Acknowledgments}

We thank Dr. Hideyasu Okada and Dr. Kensuke Kanaoka (the Department of Respiratory Medicine, Osaka Police Hospital) for their supports to the care and management of this patient.

\section{Financial Disclosure}

None to declare.

\section{Conflict of Interest}

None to declare.

\section{Informed Consent}

Informed consent was not applicable because the manuscript has been sufficiently de-identified to protect the patient.

\section{Author Contributions}

S. Saeki, K. Nishimatsu, S. Ihara and S. Minami were mainly involved in diagnosis and treatment of this patient. S. Saeki drafted the report. All authors read and critically reviewed the manuscript, and then approved the final submitted version.

\section{Data Availability}

The authors declare that data supporting the findings of this study are available within the article.

\section{References}

1. Forte MJ, Sangani RG. Emerging risk profile of lung cancer therapy: diffuse alveolar hemorrhage from osimertinib. Case Rep Oncol Med. 2019;2019:6185943.

2. Lara AR, Schwarz MI. Diffuse alveolar hemorrhage. Chest. 2010;137(5):1164-1171.

3. Schwarz MI, Fontenot AP. Drug-induced diffuse alveolar hemorrhage syndromes and vasculitis. Clin Chest Med. 2004;25(1):133-140.

4. Ieki R, Saitoh E, Shibuya M. Acute lung injury as a possible adverse drug reaction related to gefitinib. Eur Respir J. 2003;22(1):179-181.

5. Yano S, Nakataki E, Ohtsuka S, Inayama M, Tomimoto H, Edakuni N, Kakiuchi S, et al. Retreatment of lung adenocarcinoma patients with gefitinib who had experienced favorable results from their initial treatment with this selective epidermal growth factor receptor inhibitor: a report of three cases. Oncol Res. 2005;15(2):107-111.

6. Zhao CH, Liu RR, Lin L, Liu JZ, Ge FJ, Li SS, Ye $\mathrm{CY}$, et al. Diffuse alveolar hemorrhage after erlotinib combined with concurrent chemoradiotherapy in a patient with esophageal carcinoma. Int J Clin Exp Med. 2014;7(11):4492-4497.

7. Sun Z, Zeng L, Zhang M, Zhang Y, Yang N. PIM1 inhibitor synergizes the anti-tumor effect of osimertinib via STAT3 dephosphorylation in EGFR-mutant non-small cell lung cancer. Ann Transl Med. 2020;8(6):366. 
8. Sakoda Y, Kitasato Y, Kawano Y, Mizuta Y, Takata S, Kawasaki M. [A case of alveolar hemorrhage caused by gefitinib]. Nihon Kokyuki Gakkai Zasshi. 2011;49(7):506510.

9. Hirata A, Ogawa S, Kometani T, Kuwano T, Naito S, Kuwano M, Ono M. ZD1839 (Iressa) induces antiangiogenic effects through inhibition of epidermal growth factor receptor tyrosine kinase. Cancer Res. 2002;62(9):2554-2560.

10. Bruns CJ, Harbison MT, Davis DW, Portera CA, Tsan R, McConkey DJ, Evans DB, et al. Epidermal growth factor receptor blockade with $\mathrm{C} 225$ plus gemcitabine results in regression of human pancreatic carcinoma growing or- thotopically in nude mice by antiangiogenic mechanisms. Clin Cancer Res. 2000;6(5):1936-1948.

11. Pesci A, Ricchiuti E, Ruggiero R, De Micheli A. Bronchoalveolar lavage in idiopathic pulmonary fibrosis: what does it tell us? Respir Med. 2010;104(Suppl 1):S70-73.

12. Leuschner G, Behr J. Acute exacerbation in interstitial lung disease. Front Med (Lausanne). 2017;4:176.

13. Sumikawa H, Johkoh T, Colby TV, Ichikado K, Suga M, Taniguchi H, Kondoh Y, et al. Computed tomography findings in pathological usual interstitial pneumonia: relationship to survival. Am J Respir Crit Care Med. 2008;177(4):433-439. 